\title{
Electrodeposition of mixed adherent thin films of poly(ethyl acrylate) and polyacrylonitrile onto nickel
}

Noëlle Baute ${ }^{1}$, Victor M. Geskin ${ }^{2}$, Roberto Lazzaroni ${ }^{2}$, Jean-Luc Brédas ${ }^{2}$, Xavier Arys ${ }^{3}$, Alain M. Jonas ${ }^{3}$, Roger Legras ${ }^{3}$, Claude Poleunis ${ }^{4}$, Patrick Bertrand ${ }^{4}$, Robert Jérôme ${ }^{1}$, Christine Jérôme ${ }^{1}$ *

${ }^{1}$ Center for Education and Research on Macromolecules (CERM), University of Liège, Sart-Tilman B6, 4000 Liège, Belgium; Fax **32-4-3663497;

c.jerome@ulg.ac.be

${ }^{2}$ Service de Chimie des Matériaux Nouveaux, Centre de Recherche en Electronique et Photonique Moléculaires, Université de Mons-Hainaut, Place du Parc 20, 7000 Mons, Belgium; Fax **32-65-373861; Roberto.Lazzaroni@umh.ac.be

${ }^{3}$ Unité de Physique et de Chimie des Hauts Polymères, Université Catholique de Louvain, Place Croix du Sud 1, 1348 Louvain-La-Neuve, Belgium;

Fax **32-10-451593; jonas@poly.ucl.ac.be

${ }^{4}$ Laboratoire de Physico-Chimie et de Physique des Matériaux (PCPM), Université

Catholique de Louvain, Place Croix du Sud 1, 1348 Louvain-La-Neuve, Belgium;

Fax **32-10-473452; bertrand@pcpm.ucl.ac.be

(Received: July 1, 2004; published: October 7, 2004)

\begin{abstract}
Adherent thin polymer films have been prepared by sequential electrodeposition of ethyl acrylate (EA) and acrylonitrile (AN) onto nickel. Their composition has been studied by IR spectroscopy and time of flight - secondary ion mass spectrometry. Morphology and thickness have been analyzed by atomic force microscopy and ellipsometry, respectively, and compared to single component films of PEA and PAN. No microphase separation was detected in the mixed PEA/ PAN films. These show a granular morphology comparable to that of PAN films. The grains contain the two constitutive polymers, as confirmed by the selective thermal degradation of PEA.
\end{abstract}

\section{Introduction}

Much research is currently devoted to surface modification of metals in order to provide them with specific properties. Synthetic polymers play a major role as surface coatings able to impart, e.g., decorative (paint, varnish), adhesive (primer for topcoating), or electrical (antistatic) properties [1]. In addition to commonly used coating techniques (such as casting or plasma [2,3] processes), electrochemistry can also be exploited to polymerize a series of monomers at the surface of metals [4]. In this way, it is possible to combine the advantages of the electrochemical methods and the characteristic features of high polymers. Whatever the coating technique, a strong and stable adhesion to the substrate is a key issue. 
Electrochemical grafting (chemisorption) of polyacrylonitrile (PAN) onto common metals has been first proposed by Lécayon et al. [5,6] and is one method of solving this interfacial problem. Due to the huge potential of the grafting process, we have revisited [7] the cathodic reaction of acrylonitrile (AN), with the purpose of identifying the key parameters for the formation of strongly adherent polymer films [8]. Actually, the applied cathodic potential is of critical importance, since the PAN film is firmly bonded to the metal only at the less cathodic of the two peaks observed by voltammetry (Fig. 1, peak I). At the higher potential (Fig. 1, peak II), the previously grafted film undergoes a degrafting reaction and rapidly dissolves in a solvent for the polymer, in contrast to what happens at the potential of peak I. AN can also polymerize at the more cathodic potential; however the polymerization is then initiated and propagates in solution. This conclusion has been assessed recently by coupling quartz crystal microbalance and cyclic voltammetry measurements [9]. This unusual coating technique has been successfully implemented for the preparation of thin $\alpha$-emitter sources via simultaneous reduction of AN and uranium salts [10] and of electrical connectors by adequate thermal post treatment of electrografted PAN thin films [11].

Until recently, the choice of the monomer to be grafted was restricted to AN and methacrylonitrile (MAN) [12], which would constitute a severe limitation to the practical use of this technique. In an effort to understand the origin of this restriction, dependence of the electrochemical reaction on the composition of the conducting solution (mainly conducting salt and solvent) has been studied [8]. Success or failure in the grafting reaction appear to be actually controlled by a strong competition between solvent and monomer for adsorption onto the cathode in the very first step of the process $[13,14]$ : provided that the solvent is judiciously chosen, it is possible to graft onto the cathode a series of acrylic and methacrylic monomers. In these cases, voltammograms with two typical peaks are recorded, and adherent films are formed on the metal in the potential range of peak I. The extension of the electrografting process to a broad class of (meth)acrylic polymers allows new applications in relation to the availability of functional groups (e.g., epoxide, hydroxyl) able to strongly interact (or react) with another material (glass, polymer) to be joined.

Until now, characterization by a series of analytical techniques, such as time of flight secondary ion mass spectrometry (TOF-SIMS), XPS, IR, ellipsometry, atomic force microscopy (AFM), or dynamic mechanical thermal analysis has been mainly reported for PAN films grafted to the metal [15-19]. Since rubbery polymers (e.g., poly(ethyl acrylate), PEA) can now also be grafted onto metals, it is worth comparing their main characteristics to those of thermoplastic PAN films. The issue of combining two polymers in the same film is also of interest. Here EA and AN have been electrografted onto nickel in a sequential way, and composition and morphology of the mixed films have been analyzed.

\section{Results and discussion}

The first part of this work is devoted to the preparation and characterization of films of PAN and PEA. The voltammetric curves reported for these two monomers systematically show two peaks (Fig. 1). Previous studies confirmed that the inhibition peak (peak I) at the lower cathodic potential is the electrochemical signature for the deposition of an adherent film [7,9]. Therefore, the monomers have been electroreduced in the potential range of peak I, and the electrodeposited polymer, which remains attached to the cathode even in a good solvent for it, has been characterized. On the 
basis of the experimental conditions typical of the electrografting of $A N$ and EA onto nickel, mixed PAN/PEA films have been prepared by sequential polymerization of each monomer at the appropriate potential.

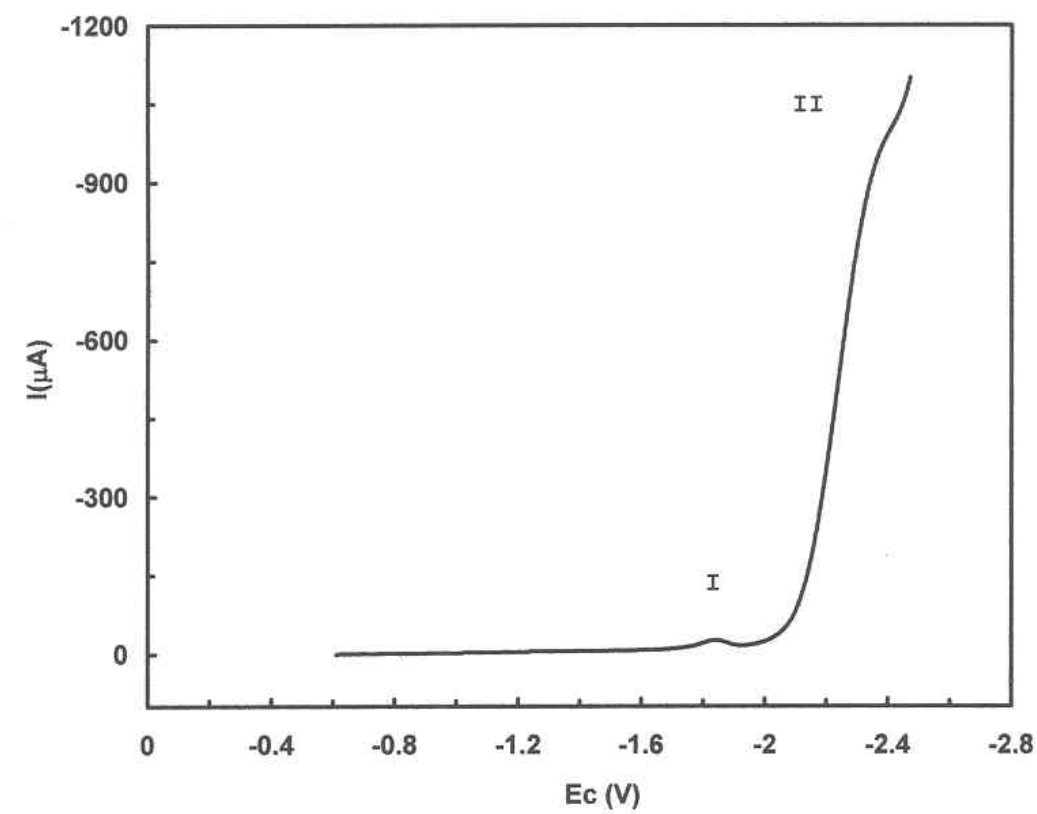

Fig. 1. Voltammetry of $\mathrm{AN}$ on nickel in a $0.05 \mathrm{M}$ tetraethylammonium perchlorate (TEAP) solution in N,N-dimethylformamide (DMF); [AN] $=0.5 \mathrm{M}, v=20 \mathrm{mV} / \mathrm{s}$

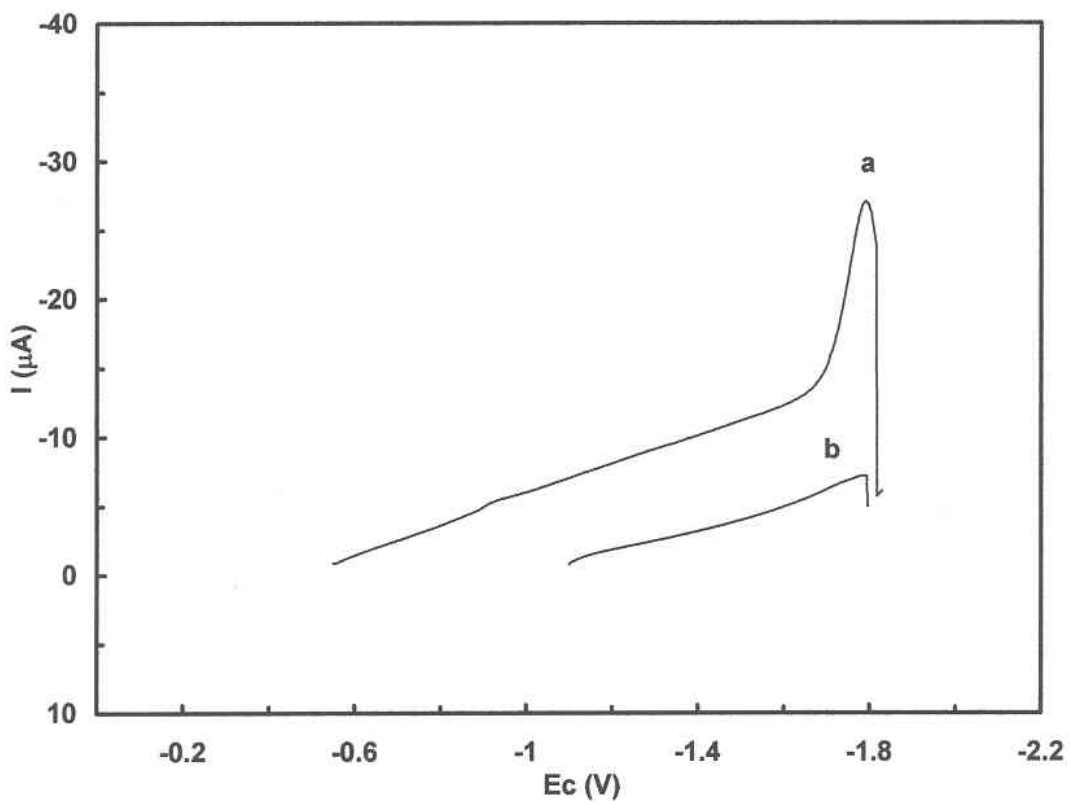

Fig. 2. Voltammetry of $A N$ on nickel in a $0.05 \mathrm{M}$ TEAP solution in DMF until the maximum of peak I: a) first scan, b) second scan; [AN] $=0.5 \mathrm{M}, v=20 \mathrm{mV} / \mathrm{s}$

\section{PAN films}

Fig. 2 shows the voltammetric response of the $0.5 \mathrm{M}$ AN solution in DMF, under cathodic polarization. During the first scan (Fig. 2a), a well-defined current peak is observed with a maximum at $-1.8 \mathrm{~V}$. When the polarization is maintained at $-1.85 \mathrm{~V}$, 
the current rapidly drops down. One reason is the rapid consumption of the monomer by the propagating species and formation of a depletion zone [21]. Moreover when the second scan is carried out, only a small residual current is recorded (Fig. 2b), which is consistent with the deposition of an insulating PAN film during the first scan.

Infrared spectroscopy confirms the deposition of a PAN film (Fig. 3A), with absorption bands at $2941 \mathrm{~cm}^{-1}\left(v_{\text {as }} \mathrm{CH}_{2}\right), 2245 \mathrm{~cm}^{-1}(v \mathrm{CN})$, and $1455 \mathrm{~cm}^{-1}\left(\delta \mathrm{CH}_{2}\right)$. There is no evidence for the occurrence of side reactions, e.g., cyclic imine formation, that would lead to a band at $1640 \mathrm{~cm}^{-1}$ [20].
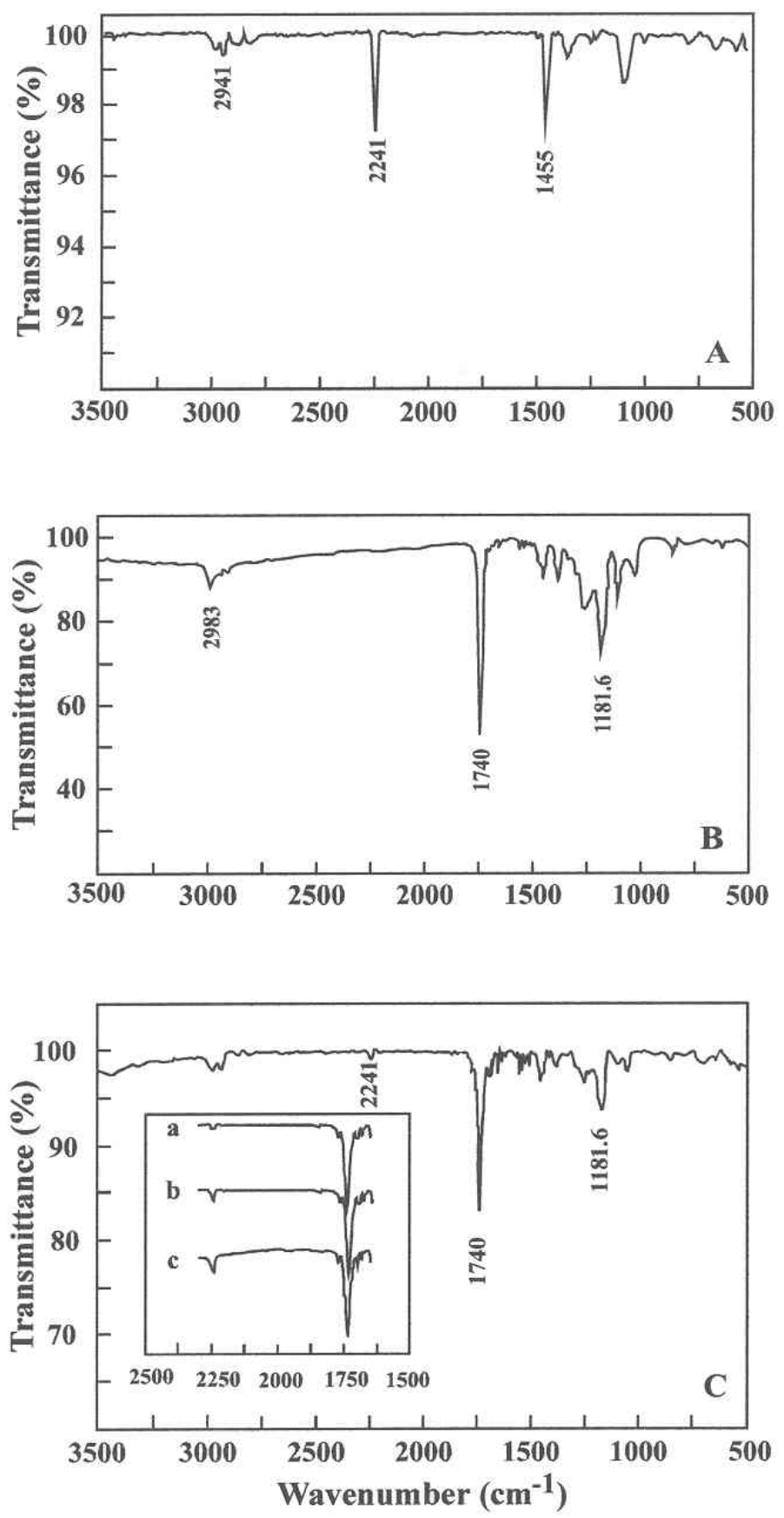

Fig. 3. Infrared spectra of polymer films deposited on $\mathrm{Ni}$ at the potential of peak I from monomer solution in DMF; A) PAN, $[A N]=1 \mathrm{M}$; B) PEA, [EA] = $2 \mathrm{M}$; C) mixed PEA/ PAN films prepared by sequential electrografting of EA $(0.5 \mathrm{M})$, followed by $\mathrm{AN}$ : a) $[\mathrm{AN}]=0.5 \mathrm{M}, \mathrm{b})[\mathrm{AN}]=2 \mathrm{M}, \mathrm{c})[\mathrm{AN}]=3 \mathrm{M}$ 
Tab. 1 shows that the intensity decreases when the monomer concentration is increased and that in parallel the grafted film becomes thicker as a result of a more favourable propagation/termination balance for the growing chains [17]. The film thickness measured by ellipsometry generally does not change by more than $10 \%$ with the area probed on the same sample or on samples prepared in the same batch [17]. In contrast, larger variation can be observed when the thickness of samples prepared in different batches is compared, indicating that minor modifications in the preparation of the electrode surface and the electrochemical solution can have a strong effect [17]. Special care has thus been taken for the preparation of all the samples listed in Tab. 1, so as to make the comparison reliable.

Tab. 1. Dependence of ip $1_{\mathrm{AN}}$ and ip $1_{\mathrm{EA}}$ (ip1: current intensity at the maximum of peak 1) and the film thickness measured by ellipsometry on the monomer concentration in DMF; [TEAP] $=5 \cdot 10^{-2} \mathrm{M}, v=20 \mathrm{mV} / \mathrm{s}$

\begin{tabular}{ccccc}
\hline $\begin{array}{c}\text { [monomer] } \\
\text { in mol/l }\end{array}$ & ip1 in $\mu \mathrm{A}$ & thickness in nm & ip1 in $\mu \mathrm{A}$ & thickness in $\mathrm{nm}$ \\
\hline 0.5 & 26 & 42.9 & 500 & 37.9 \\
0.7 & - & - & 460 & 49.1 \\
1 & 19 & 54.3 & 400 & 75 \\
1.5 & 16 & 66.3 & 340 & 98.9 \\
2 & 14 & 75.8 & 300 & 122.5 \\
2.5 & 10 & 82.1 & - & -
\end{tabular}

The morphology of the PAN films has been observed by atomic force microscopy. When the polymer is formed in acetonitrile (ACN), which is a non-solvent for PAN, films have a granular aspect $[7,18]$. This observation can be explained by the rapid precipitation of the chains growing from the cathode surface. In order to minimize the unfavourable contacts with the solvent, the precipitated chains tend to agglomerate in the form of grains rather than to spread over the whole metal-solution interface.

In a solvent for the polymer and at low AN concentration $(0.2 \mathrm{M})$, the PAN film is too thin to be clearly discerned on the surface of the polished polycrystalline nickel plates used in this work as electrodes (Fig. 4); note the presence of long characteristic ridges, probably resulting from polishing. At $0.5 \mathrm{M}$ AN concentration, the morphology of the polymer is already distinct; a granular deposition of PAN is observed as in $A C N$, the size of the grains increasing with the monomer concentration. For instance, the grain average diameter and height increase from $40 \mathrm{~nm}$ and $3 \mathrm{~nm}$ up to $100 \mathrm{~nm}$ and $10 \mathrm{~nm}$, respectively, when the AN concentration increases from $0.5 \mathrm{M}$ to $2 \mathrm{M}$ (Fig. 5A and B). Note that the height determined with AFM does not correspond to the actual thickness of the films since the grains are not isolated on the surface but are partially merged.

It is quite surprising that the morphology of the PAN films is granular, whatever the solvent used for the preparation. Indeed, the deposition of a grafted polymer coating in a solvent for this polymer is not a nucleation-and-growth process: the chains while growing are solvated and thus must be fairly extended. We have shown that in DMF the grains' size increases with the monomer concentration to a greater extent than it is the case in ACN [22]. Thus, in contrast to what happens when films are prepared in 
ACN, aggregation does come into play when the polymerization is already over, i.e., during precipitation of the non-grafted ends of the chains onto the surface upon washing with a non-solvent of the polymer (washing by DMF followed by ACN, see Exptl. part). Furthermore, these films have been dried and observed by AFM below the glass transition temperature $T_{\mathrm{g}}\left(150^{\circ} \mathrm{C}\right.$ [23]), which prevents any reorganization of the chains when in contact with air.

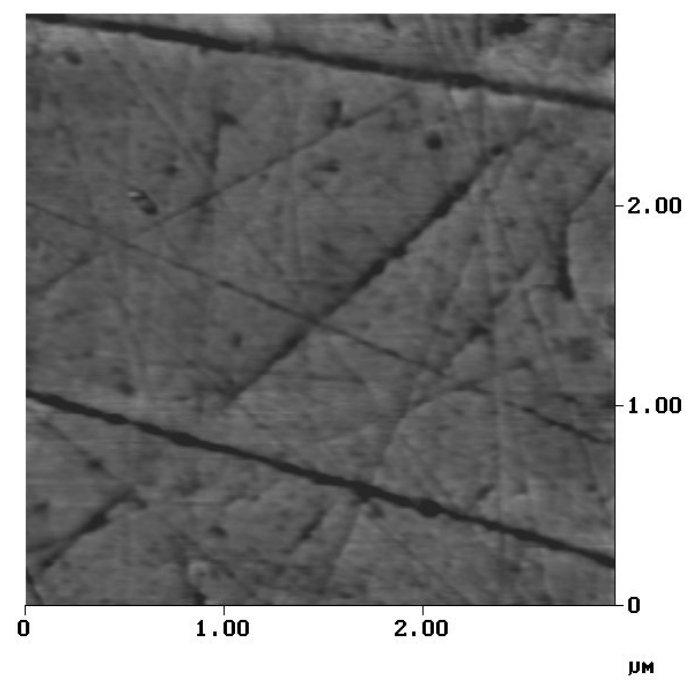

Fig. 4. Atomic force micrograph ( $3 \mu \mathrm{m} \times 3 \mu \mathrm{m} \times 50 \mathrm{~nm}$ ) of a PAN film deposited on $\mathrm{Ni}$ at the potential of peak I from 0.2 M AN solution in DMF
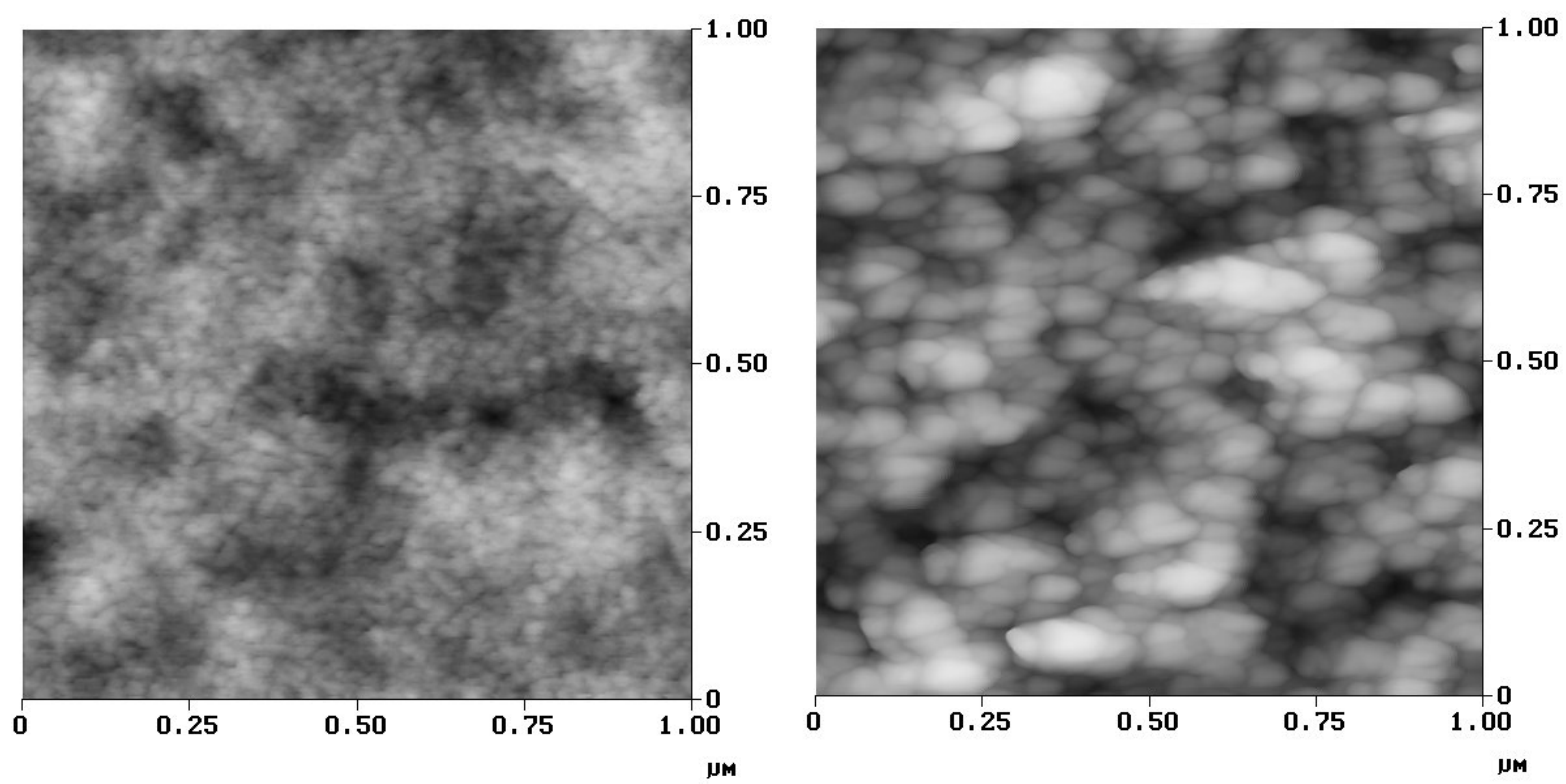

Fig. 5. Atomic force micrographs of PAN films deposited on $\mathrm{Ni}$ at the potential of peak I; A) left: from $0.5 \mathrm{M}$ AN solution in DMF (1 $\mu \mathrm{m} \times 1 \mu \mathrm{m} \times 50 \mathrm{~nm})$, B) right: from $2 \mathrm{M}$ AN solution in DMF $(1 \mu \mathrm{m} \times 1 \mu \mathrm{m} \times 100 \mathrm{~nm})$

That the grain size increases with monomer concentration is not the consequence of an increase in the chain grafting density. Indeed, Crispin et al. have shown [14] that $\mathrm{AN}$ is much more strongly adsorbed onto $\mathrm{Ni}$ than the solvent molecules. This suggests that when the nickel electrode is put in the electrochemical medium the 
metal surface gets covered by a monolayer of AN molecules, whatever the solvent and the AN concentration. Therefore, the grafting density of AN is expected to be independent of the monomer concentration. That the grains size increases with monomer concentration indicates that chain termination is delayed at the benefit of chain propagation, which is a characteristic commonly observed for polyaddition reactions. The longer the chain, the larger the volume of the coil precipitating, the larger the grains, which are made of a number of adjacently grafted chains. The easier PAN chain propagation in DMF compared to ACN $[9,17]$ thus explains the larger variation of the grain size in this solvent.

\section{PEA films}

The cathodic response of $0.5 \mathrm{M}$ EA solution in DMF (Fig. 6) is similar to the one observed for AN (Fig. 2), all the other conditions being the same. Two significant differences must be noted: the more cathodic potential at the maximum of peak I and the higher intensity of this peak when EA is substituted for AN (Tab. 1). Since it might be argued that the comparison of peak potentials measured for non-identical solutions vs. a pseudo-reference is not straightforward, it is worth noting that the peak maximum is observed $1.35 \mathrm{~V}$ beyond the open-circuit potential in the case of EA compared to $1.25 \mathrm{~V}$ in the case of AN. Furthermore, Yamazaki et al. [24] have reached the same conclusion, by measuring the half-wave reduction potential of various monomers in DMF vs. SCE, i.e., the easier reduction of AN than of EA in this solvent. The higher ip1 intensity when EA is electrografted rather than AN indicates that the cathode is more slowly passivated, although no clear explanation can be proposed to explain this observation. As for $A N$, the intensity of peak $I$ is also dependent on EA concentration (Tab. 1). IR analysis of the PEA film (Fig. 3B) typically shows the stretching vibrations of the carbonyl and of the $\mathrm{C}-\mathrm{O}$ bonds at 1740 and $1181 \mathrm{~cm}^{-1}$, respectively [25].

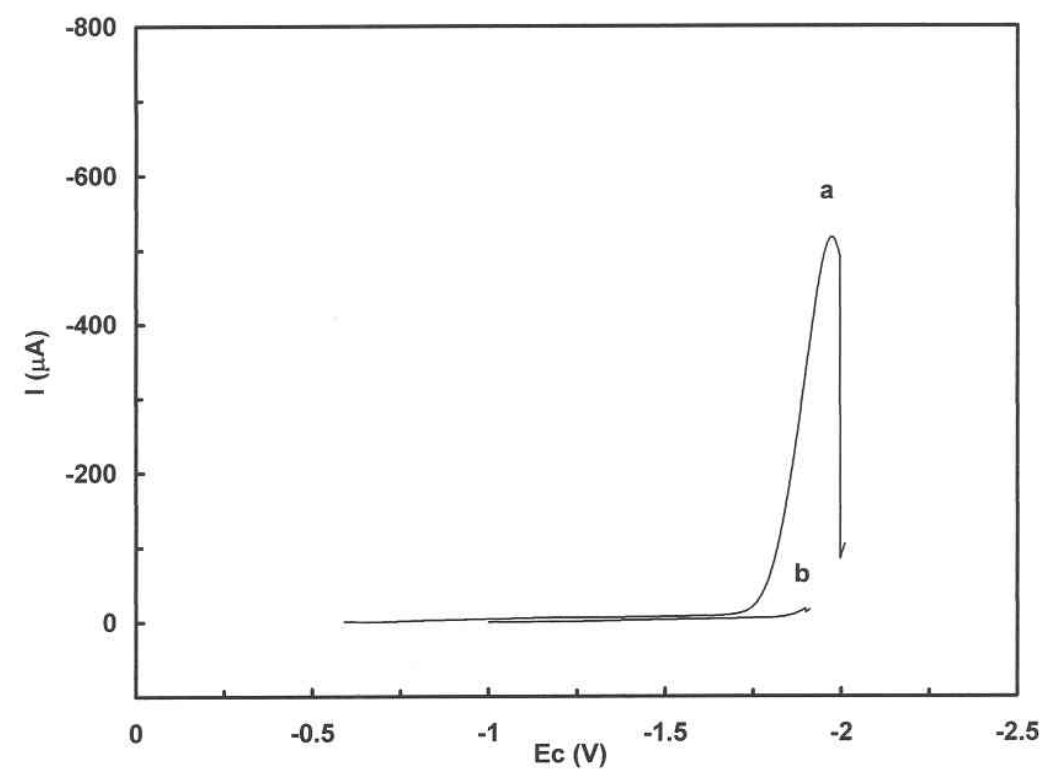

Fig. 6. Voltammetry of EA on nickel in a $0.05 \mathrm{M}$ TEAP solution in DMF until the maximum of peak I: a) first scan, b) second scan; $[E A]=0.5 \mathrm{M}, v=20 \mathrm{mV} / \mathrm{s}$

Fig. 7 shows the experimental ellipsometric $\psi$ and $\Delta$ angles for PEA samples prepared at different monomer concentrations. At a given angle of incidence, the 
experimental data align on a continuous curve in the $(\psi, \Delta)$ plane. $(\psi, \Delta)$ rotates clockwise along these curves upon increasing film thickness. For non-absorbing films such as PEA and PAN films, $(\psi, \Delta)$ returns to the $0-\mathrm{nm}$ point after a given period $\left(\mathrm{PEA} 70.3^{\circ}=280.4 \mathrm{~nm}\right.$; PAN $\left.70.3^{\circ}=267.7 \mathrm{~nm}\right)$. Fig. 8 compares the dependence of the film thickness on the monomer concentration for PAN and PEA. Similarly to PAN films formed in DMF [17], the increase in PEA film thickness does not show any tendency to level off in the range of concentrations studied, in line with growth of the solvated grafted chains proportional to monomer concentration and much faster than termination. It must be noted that PEA films become rapidly thicker than PAN films, all the other conditions being the same.

Whatever the thickness, the morphology of the PEA films is featureless when observed with AFM (Fig. 9). The origin of the marked difference to PAN has to be found in the low $T_{\mathrm{g}}$ of PEA $\left(-24^{\circ} \mathrm{C}\right)$ [23], which allows this rubbery material to flow and to cover completely the surface of the cathode.

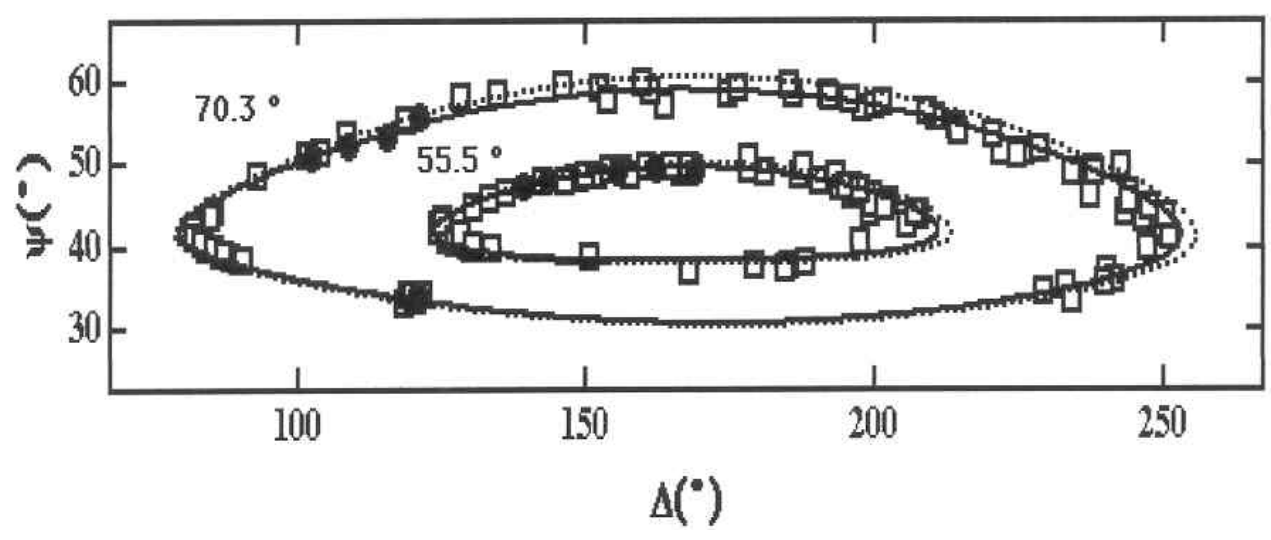

Fig. 7. Comparison of the experimental ellipsometric angles, $\Psi$ and $\Delta$, for PEA (squares), and the theoretical curves for PAN (dashed line) and PEA (continuous line) computed with the parameters given in the Exptl. part. 'Circles' refer to the mixed PEA/PAN films

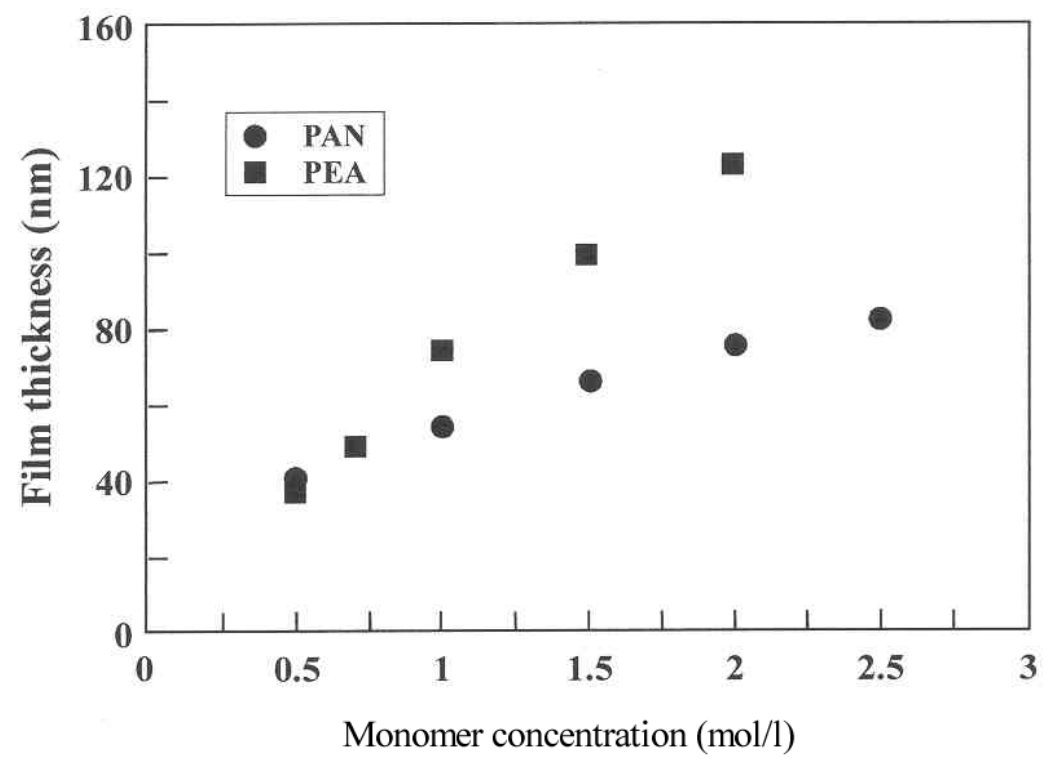

Fig. 8. Dependence of the film thickness on the monomer concentration in DMF 


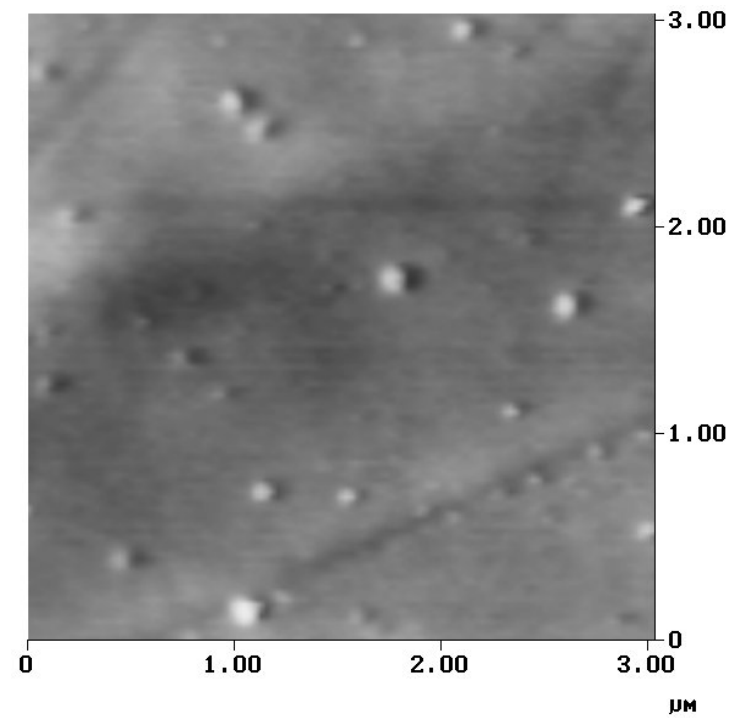

Fig. 9. Atomic force micrograph $(3 \mu \mathrm{m} \times 3 \mu \mathrm{m} \times 50 \mathrm{~nm})$ of a PEA film deposited on $\mathrm{Ni}$ at the potential of peak I from 0.5 M EA solution in DMF

\section{Mixed PAN/PEA films}

The electroreduction of a mixture of two monomers, AN and EA, has been first carried out. Although of mixed composition, the films are very thin and heterogeneous as shown by AFM [26]. This phenomenon is explained by a competition between the two monomers for adsorption onto the cathode sites, which in addition to the already mentioned monomer/solvent competition perturbs the electrografting reaction. Therefore, the best way to overcome this problem is to polymerize the monomers in a sequential way, thus using two electrochemical cells, each containing one monomer. Of course, either of the two polymerization sequences can be considered, i.e., polymerization of AN first followed by EA and vice versa.

\section{PAN grafting first}

PAN has been first electrografted onto $\mathrm{Ni}$ from a $0.5 \mathrm{M}$ AN solution in DMF, as discussed before. The cathode has then been rinsed with pure DMF, before being dipped into 0.5 M EA solution in DMF. Fig. 10a shows a voltammetric peak that is observed at a more cathodic potential compared to the use of bare nickel as a cathode (Fig. 10b). In those conditions, EA peak I and peak II are poorly resolved so that the formation of a perfectly adherent PEA film is highly perturbed by the formation of non-grafted PEA chains in the close vicinity of the cathode. The most surprising observation is that, although the cathode is almost fully passivated after the first scan in the AN solution (Fig. 2), the electrochemical signature for the PEA grafting is clearly observed. The only reasonable explanation is that at least part of the nickel surface has been made available to the EA reaction, which is consistent with the more cathodic potential at which PEA has been grafted compared to PAN during the first scan (comparison of Figs. 10a and 10c), thereby allowing the degrafting of at least part of the originally chemisorbed PAN chains [7,9]. The coating is heterogeneous as seen with the naked eye. When the cathode is rinsed with DMF (a good solvent for the two polymers) and dried, only infrared absorption bands characteristic of PEA are observed (not shown). This electropolymerization sequence is thus clearly unfavourable to the formation of an adherent mixed polymer film. 


\section{PEA grafting first}

When the polymerization sequence is reversed, the same qualitative observation is also reported, i.e., the intensity of the PAN passivation peak (Fig. 10d) is smaller and the potential at the peak maximum is more cathodic compared to experiments conducted on bare nickel cathodes (Fig. 10c). In agreement with the less cathodic potential used for AN grafting (second step) compared to EA (first step) (comparison of Figs. 10d and 10b), the intensity of the inhibition peak characteristic of PAN grafting is substantially decreased, indicating that at least part of the originally grafted PEA chains remain strongly bound to the cathode.

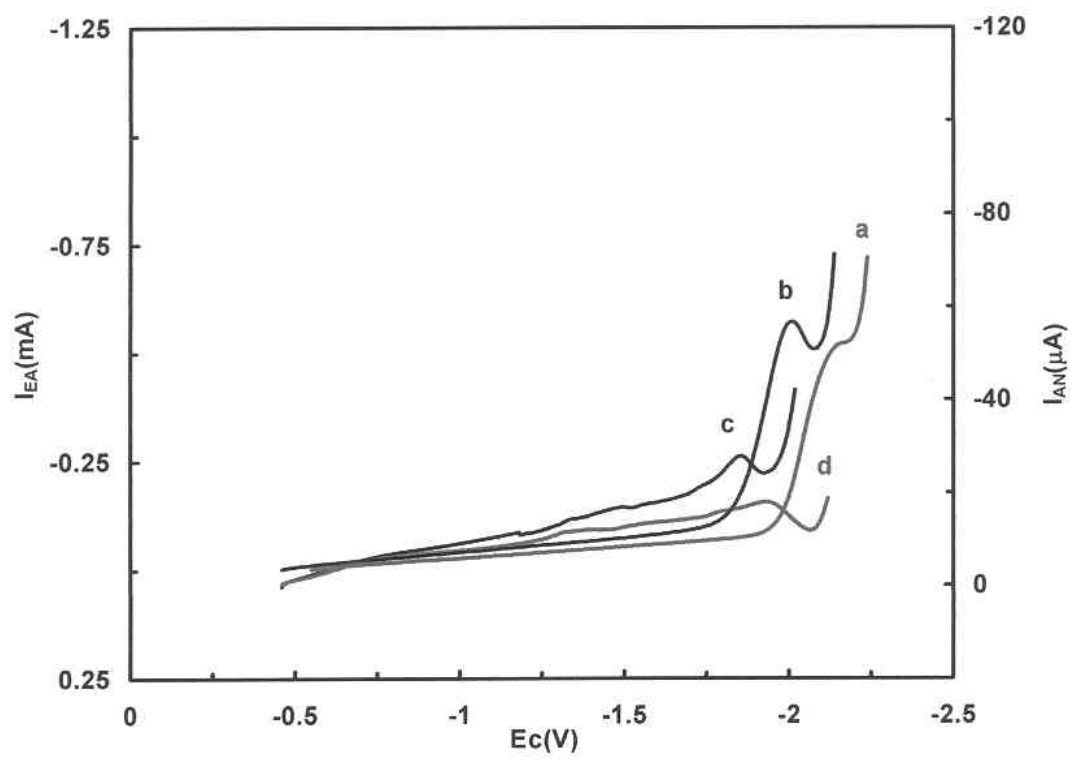

Fig. 10. Cathodic response of $0.5 \mathrm{M}$ EA solution in DMF: a) on Ni previously grafted by PAN from $0.5 \mathrm{M}$ AN solution; b) on Ni. Cathodic response of $0.5 \mathrm{M}$ AN solution in DMF: $c$ ) on $\mathrm{Ni}$; d) on Ni previously grafted by PEA from $0.5 \mathrm{M}$ EA solution. [TEAP] = $0.05 \mathrm{M}, v=20 \mathrm{mV} / \mathrm{s}$

This assumption is confirmed by infrared analysis (Fig. 3C) that clearly shows absorption bands for both the $C \equiv N\left(2241 \mathrm{~cm}^{-1}\right)$ and $C=O\left(1740 \mathrm{~cm}^{-1}\right)$ stretching vibrations, even though the cathode has been rinsed with DMF. Furthermore, in contrast to the former polymerization sequence, the inhibition peak caused by the second monomer is well separated from the origin of peak II so that initiation and propagation of the AN polymerization in solution can be more efficiently prevented from occurring. It is thus more adequate to polymerize EA first followed by AN. These observations indicate that the grafted PEA film, which appears continuous in the AFM image (thus in the dry state), leaves room for AN penetration and subsequent grafting of PAN chains. Solvation of the PEA chains by the electrolytic solution (AN/DMF) is only part of the explanation. According to theoretical calculations by Crispin et al. [14], EA is less strongly adsorbed onto nickel than AN and thus less prone than AN to displace the solvent molecules for being adsorbed onto the cathode sites. Thus, the $\mathrm{Ni}$ surface, which is thought to be covered by a monolayer of AN molecules in DMF, would not be completely covered by EA at the same concentration ( $0.5 \mathrm{M})$ in DMF. Therefore, PEA chains would be grafted sparsely enough to leave sites available to AN adsorption and grafting (Scheme 1). 
Cathode coverage in solution 1

( $S$ is the solvent)

\begin{tabular}{|lll|}
\hline AN & AN & AN \\
AN & AN & AN \\
AN & AN & AN \\
\hline
\end{tabular}

\begin{tabular}{|ccc|}
\hline$E A$ & $S$ & $E A$ \\
$S$ & $E A$ & $S$ \\
$E A$ & $S$ & $E A$ \\
\hline
\end{tabular}

Electrografting $\stackrel{\text { of } A N}{\longrightarrow}$

Electrografting of EA
$\mathrm{X}$ are cathode sites available for the adsorption of AN in solution 2
PAN is degrafted at the potential required by the electrografting of EA
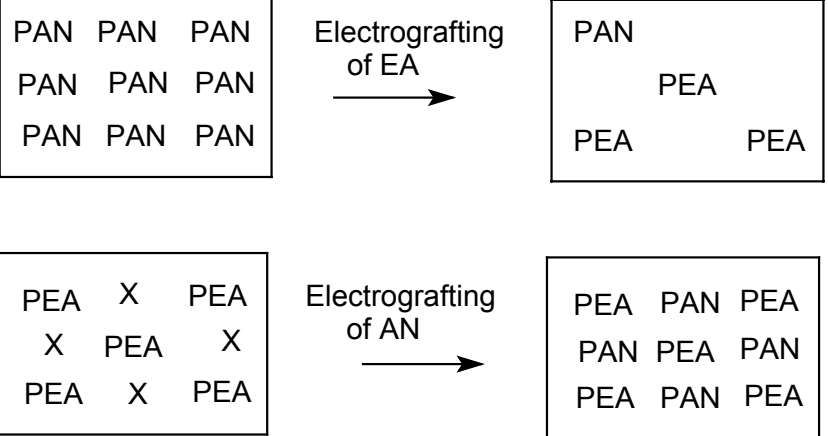

PEA PAN PEA

PAN PEA PAN

PEA PAN PEA

Scheme 1

In order to change the composition of the mixed PEA/PAN films, concentration of EA in the first polymerization step has been kept constant $(0.5 \mathrm{M})$, whereas the $\mathrm{AN}$ concentration has been changed in the second cell from 0.5 to $3.0 \mathrm{M}$. The intensity of the inhibition peak (ip $1_{\mathrm{AN}}$ ) is observed to decrease upon increasing the AN concentration, as the direct electrografting of AN on bare nickel (Tab. 2).

Tab. 2. Dependence of ip $1_{\mathrm{AN}}$ on the acrylonitrile concentration during the second scan performed on the cathode precoated by PEA during the first scan, $[E A]=0.5 \mathrm{M}$

\begin{tabular}{c|cccc} 
& {$[\mathrm{AN}]=0.5 \mathrm{M}$} & {$[\mathrm{AN}]=1 \mathrm{M}$} & {$[\mathrm{AN}]=2 \mathrm{M}$} & {$[\mathrm{AN}]=3 \mathrm{M}$} \\
\hline ip1 $1_{\mathrm{AN}}$ in $\mu \mathrm{A}$ & 24 & 20 & 18 & 14
\end{tabular}

The relative intensity of the IR absorption of the $\mathrm{CN}$ group also increases compared to the $\mathrm{CO}$ absorption, which confirms that more PAN is formed when the AN concentration is increased (Fig. $3 \mathrm{C} \mathrm{a,b}, \mathrm{c}$ ). In order to get more quantitative information, the mixed PEA/PAN films have been analyzed ex situ by infrared reflection-absorption spectroscopy (IRRAS). The relative amount of the two polymers has been estimated from the experimental area of the carbonyl and nitrile absorption bands and a calibration curve. These data are listed in Tab. 3.

Tab. 3. Composition (in wt.-\%) of mixed PEA/PAN films prepared at constant EA concentration $(0.5 \mathrm{M})$ and different AN concentrations in DMF

\begin{tabular}{cc}
\hline$[\mathrm{AN}]$ in $\mathrm{mol} / \mathrm{l}$ & PAN in wt.- $\%$ \\
\hline 0.5 & 20 \\
1 & 26 \\
2 & 44 \\
3 & 60
\end{tabular}

It is clear that when the concentration of the two monomer solutions is the same, the mixed film contains much more PEA (grafted in the first step) than PAN. This 
conclusion is also supported, at least qualitatively, by the ellipsometric analysis of a mixed film prepared from $2 \mathrm{M}$ solution of each monomer. Indeed, the experimental $\Psi$ and $\Delta$ values are closer to the theoretical curve for PEA than to the one for PAN (Fig. 7 ), which indicates that the effective refractive index of the mixed film is closer to the refractive index of PEA. Within the limits of the effective medium approximation $[27,28]$, it can be concluded that the mixed film mainly contains PEA. Since both IR reflection-absorption spectroscopy and ellipsometry essentially provide information on the bulk composition, a surface sensitive technique such as time-of-flight secondary ion mass spectrometry (TOF-SIMS) is desirable to evaluate the actual chemical composition of the film surface.
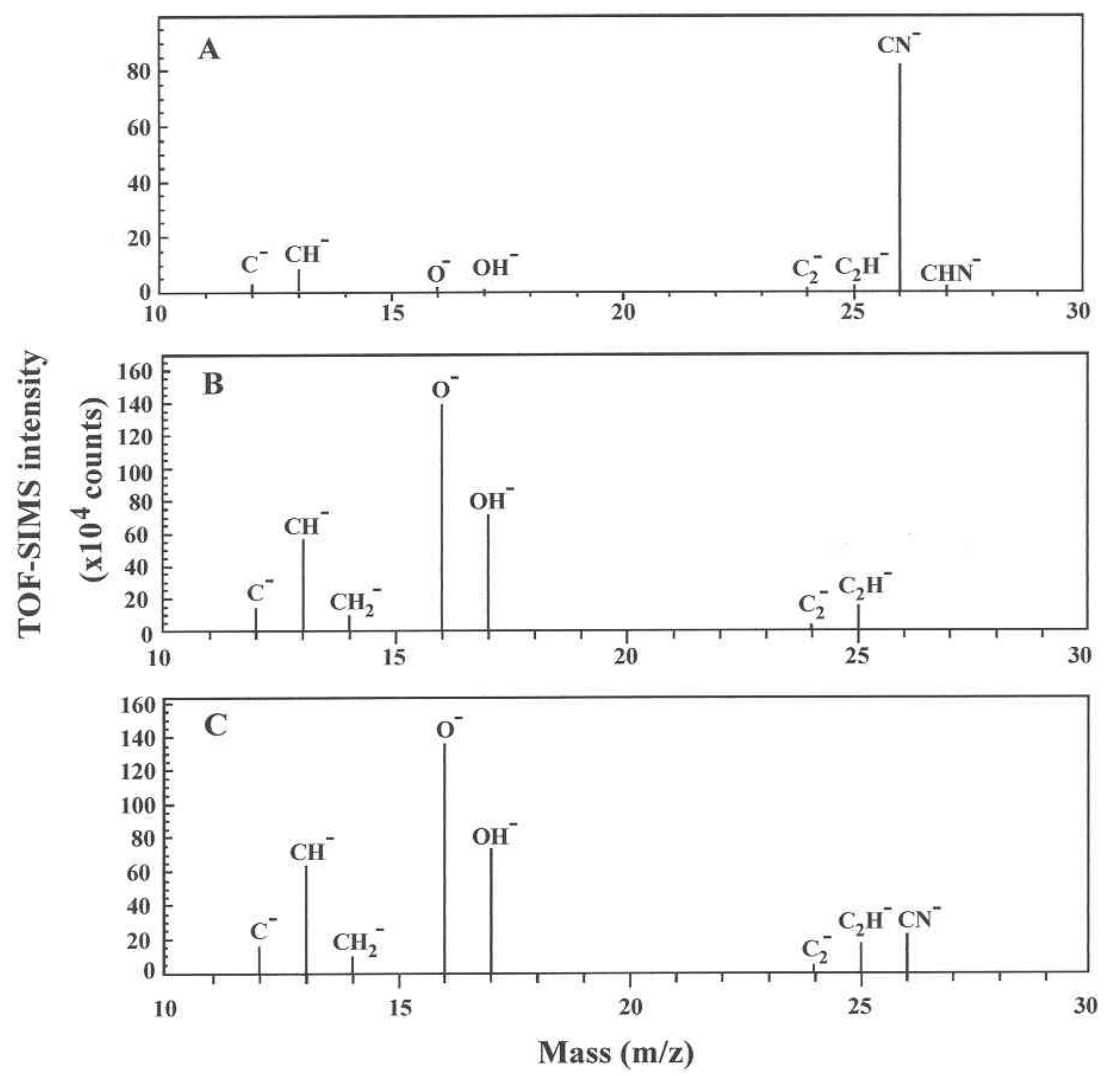

Fig. 11. TOF-SIMS negative spectra (in the $0-30 \mathrm{~m} / \mathrm{z}$ mass range) of A) PAN film; $[A N]=0.5 \mathrm{M}$; B) PEA film, $[E A]=0.5 \mathrm{M} ; \mathrm{C}$ ) mixed PEA/PAN film, $[A N]=[E A]=0.5 \mathrm{M}$

The TOF-SIMS negative spectra for PAN, PEA, and mixed PEA/PAN films are compared in two mass ranges: $10-30$ and $30-100 \mathrm{~m} / \mathrm{z}$ (Figs. 11 and 12). All the samples have been prepared from $0.5 \mathrm{M}$ monomer solutions in DMF. Figs. $11 \mathrm{~A}$ and $12 \mathrm{~A}$ show the fragmentation pattern characteristic of PAN [29], which is dominated by the peak at $26 \mathrm{~m} / \mathrm{z}$ related to $\mathrm{CN}^{-}$. Additional peaks at 38, 39, 40,50,51, 52, 62, 63, 64 and $91 \mathrm{~m} / z$ are characteristic of $\mathrm{C}_{x} \mathrm{H}_{y} \mathrm{~N}_{z}{ }^{-}$, and thus of the AN structure. The peak at $42 \mathrm{~m} / \mathrm{z}\left(\mathrm{CNO}^{-}\right)$indicates that the PAN film is slightly oxidized. The small peaks at 16,17 and $32 \mathrm{~m} / \mathrm{z}$ (assigned to $\mathrm{O}^{-}, \mathrm{OH}^{-}$and $\mathrm{O}_{2}{ }^{-}$) are consistent with the oxidation of PAN film or indicate some residues of the conducting salt. Indeed, all the spectra of Fig. 12 show some peaks characteristic of TEAP at 35, 37, 67, 69, 83, 85 and 99 $\mathrm{m} / \mathrm{z}$, assigned to the isotopes of $\mathrm{Cl}^{-}$or to $\mathrm{ClO}_{x}{ }^{-}$fragments. This contamination is, however, very small. 

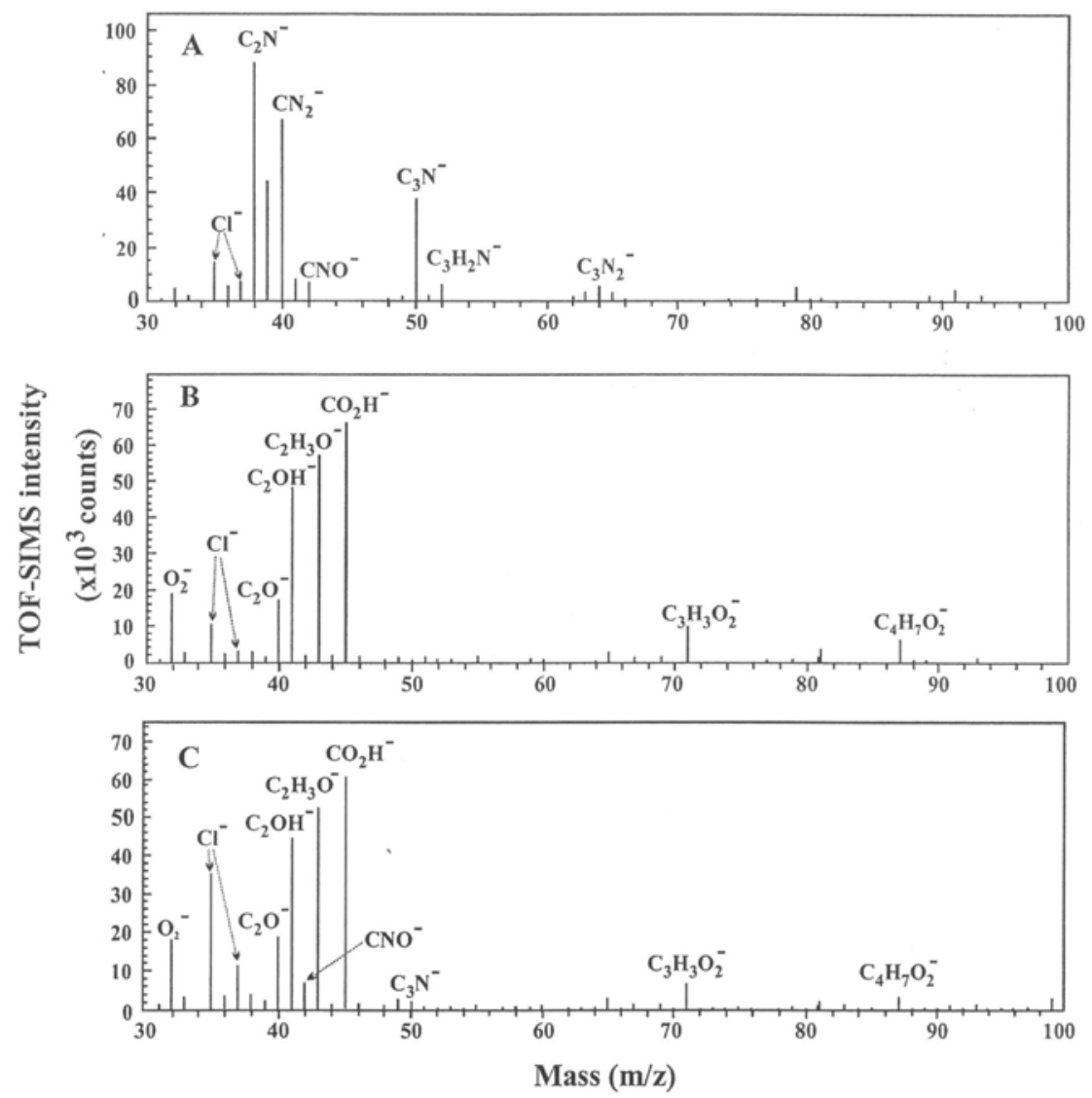

Fig. 12. TOF-SIMS negative spectra (in the $30-100 \mathrm{~m} / \mathrm{z}$ mass range) of A) PAN film; $[A N]=0.5 \mathrm{M}$; B) PEA film, $[E A]=0.5 \mathrm{M} ; \mathrm{C}$ ) mixed PEA/PAN film, $[A N]=[E A]=0.5 \mathrm{M}$

The TOF-SIMS spectra of the PEA film are dominated by the peak at $16 \mathrm{~m} / \mathrm{z}$ (Fig. 11B) assigned to $\mathrm{O}^{-}$. The peaks at $40,41,43,45,71$ and $87 \mathrm{~m} / \mathrm{z}$ are characteristic of $\mathrm{C}_{x} \mathrm{H}_{y} \mathrm{O}_{z}{ }^{-}$(Fig. 12B), in agreement with the fragmentation pattern usually reported for PEA [29]. Additional peaks (not shown here) at 127, 139, 153 and $185 \mathrm{~m} / \mathrm{z}$ correspond to the $\mathrm{C}_{7} \mathrm{H}_{11} \mathrm{O}_{2}{ }^{-}, \mathrm{C}_{7} \mathrm{H}_{7} \mathrm{O}_{3}{ }^{-}, \mathrm{C}_{8} \mathrm{H}_{9} \mathrm{O}_{3}{ }^{-}$and $\mathrm{C}_{9} \mathrm{H}_{13} \mathrm{O}_{4}{ }^{-}$fragments.

The spectra for the mixed PEA/PAN film are the superposition of the fragmentation patterns for the two constitutive polymers. Most of the peaks characteristic of each polymer are clearly observed in Figs. $11 \mathrm{C}$ and $12 \mathrm{C}$. The intensity of the peaks assigned to PAN is, however, small compared to that one of peaks characteristic of PEA, which indicates a larger amount of PEA at the surface and is in line with the bulk composition estimated by IR analysis of the 0.5 M EA / 0.5 M AN film (Tab. 3). It is, however, noteworthy that the peaks characteristic of PAN are no longer observed by TOF-SIMS when the mixed film is prepared from more concentrated solutions (2 M EA / 2 M AN), indicating that PEA then covers the surface of the film. This observation is explained from the data of Fig. 8: the PEA and PAN films are of comparable thickness when prepared from $0.5 \mathrm{M}$ solution in DMF, whereas the PEA films are definitively thicker than the PAN films when the monomer concentration is $2 \mathrm{M}$. If this difference is maintained in the formation of the mixed films, it is not surprising that the films prepared from $2 \mathrm{M}$ monomer solutions are covered by PEA (Scheme 2).

AFM has been recently used in tapping mode in order to detect microphase separation in polymers on the 10-nm scale [30]. In case of the mixed films prepared in this study, no microphase separation of PEA and PAN is observed even when the two constitutive polymers are detectable on the surface by TOF-SIMS. Furthermore, it 
must be noted that even at a low PAN content (20 wt.-\%, Tab. 3), the morphology of the film is clearly granular (Fig. 13A), as it is the case for pure PAN films. Furthermore, the size of the grains is larger for mixed films compared to pure PAN films prepared with the same AN concentration (Fig. 5A). This suggests that PAN dictates its morphology to the more flexible PEA chains in grains of mixed composition, as will be confirmed below. Cracks that are observed in some places of the PEA/PAN film (Fig. 13B) might have been initiated by defects (groves, ridges) at the surface of the $\mathrm{Ni}$ cathode as a result of strain developed upon drying. The apparent depth of these cracks is however small $(\approx 5 \mathrm{~nm})$ compared to the film thickness. The morphology of the mixed films prepared from more concentrated solutions $(2 M)$ is featureless, in agreement with TOF-SIMS observations and the complete coverage by rubbery PEA chain segments.

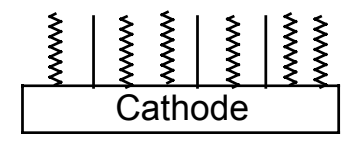

$[\mathrm{AN}]=[\mathrm{EA}]=0.5 \mathrm{M}$

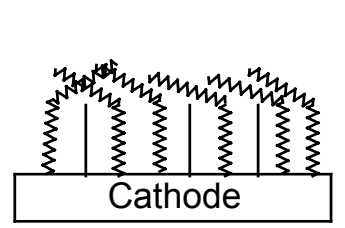

PEA = mun

PAN $=$

$[A N]=[E A]=2 M$

\section{Scheme 2}
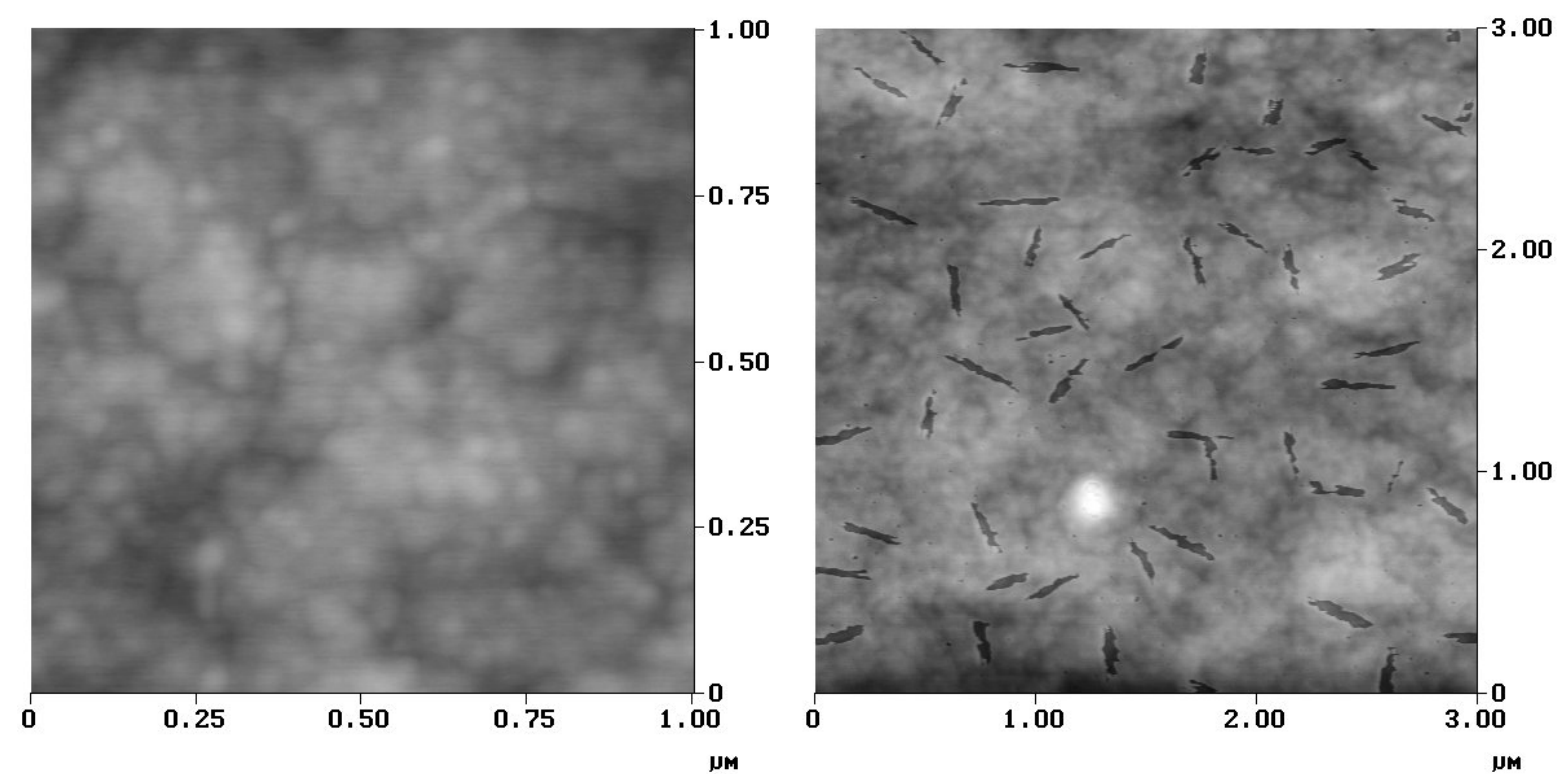

Fig. 13. Atomic force micrographs of a mixed PEA/PAN film prepared by sequential electrografting from a $0.5 \mathrm{M} \mathrm{EA}$ and then from $0.5 \mathrm{M}$ AN solutions in DMF: A) left: $1 \mu \mathrm{m} \times 1 \mu \mathrm{m} \times 50 \mathrm{~nm}, \mathrm{~B})$ right: $3 \mu \mathrm{m} \times 3 \mu \mathrm{m} \times 50 \mathrm{~nm}$ (another location)

Films prepared at higher AN concentration ( $3 \mathrm{M}$ ) and thus containing more PAN (60 wt.-\%, Tab. 3) consist of better-defined grains (Fig. 14), which is an expected evolution since the morphology-dictating partner becomes the major component. In order to gain further information on the length scale of the polymer mixing components, the 
thermal behaviour of the mixed PEA/PAN films has been analyzed since PEA and PAN have a completely different behaviour when heated at high temperature. PEA is known to degrade into gaseous products, whereas the structure of PAN is changed into a cyclic structure, which is a carbon fibre precursor [31,32].

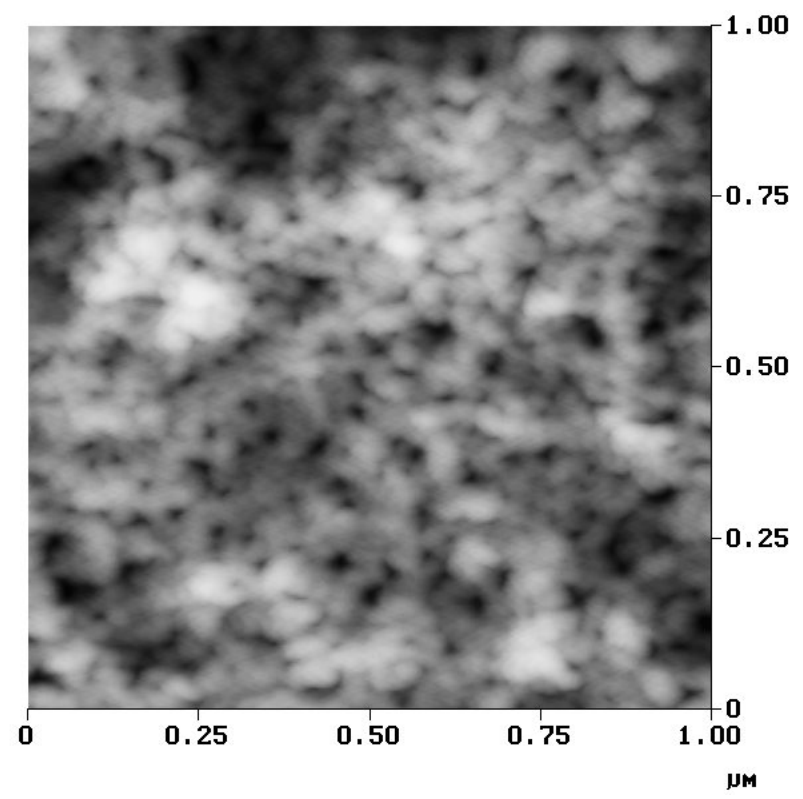

Fig. 14. Atomic force micrograph $(1 \mu \mathrm{m} \times 1 \mu \mathrm{m} \times 50 \mathrm{~nm})$ of a mixed PEA/PAN film prepared by sequential electrografting from a $0.5 \mathrm{M}$ EA solution in DMF, followed by electrografting from AN solution in DMF; $[A N]=3 \mathrm{M}$

It is therefore possible to remove PEA selectively, a process which could reveal the initial morphology of the PEA/PAN films. Samples have been heated in an oven at a rate of $5^{\circ} \mathrm{C} / \mathrm{min}$ up to $400^{\circ} \mathrm{C}$ and maintained at this temperature for $1 \mathrm{~h}$. Heating and cooling were carried out under nitrogen flow. The stability of the nickel surface upon long heating treatment has also been ascertained.

According to Grassié and Speakman [25], poly(alkyl acrylate)s degrade in a singlestage process starting at $300^{\circ} \mathrm{C}\left(350^{\circ} \mathrm{C}\right.$ in case of PEA). The main volatile products are carbon dioxide and the parent olefin and alcohol of the alkyl group. Some polymer fragments can also be found. The PEA sample shown in Fig. 9 has been heated at $400^{\circ} \mathrm{C}$ for $1 \mathrm{~h}$, which leaves a surface with the main characteristics of the original Ni plate plus some residual polymer grains (Fig. 15). Most of the PEA film has thus been eliminated by the annealing process. $250^{\circ} \mathrm{C}$ is the upper limit commonly accepted for the thermal stability of PAN [33]. Upon annealing at $400^{\circ} \mathrm{C}$, thus well above the PAN melting temperature $\left(317^{\circ} \mathrm{C}\right.$ according to Krigbaum and Tokita [33]), the PAN coating morphology is expected to be deeply modified.

Actually, the well-defined granular structure of PAN films (Fig. 5A) is lost in favour of very irregularly shaped aggregates (Fig. 16A). This observation is in close agreement with recently published AFM images of electrografted PAN treated at high temperature [18]. As soon as physical transformations (softening and flowing of the polymer) and chemical transformations (cyclization, cross-linking and release of gaseous products) occur, the original structure of the film changes rapidly and the porosity of the surface increases. 


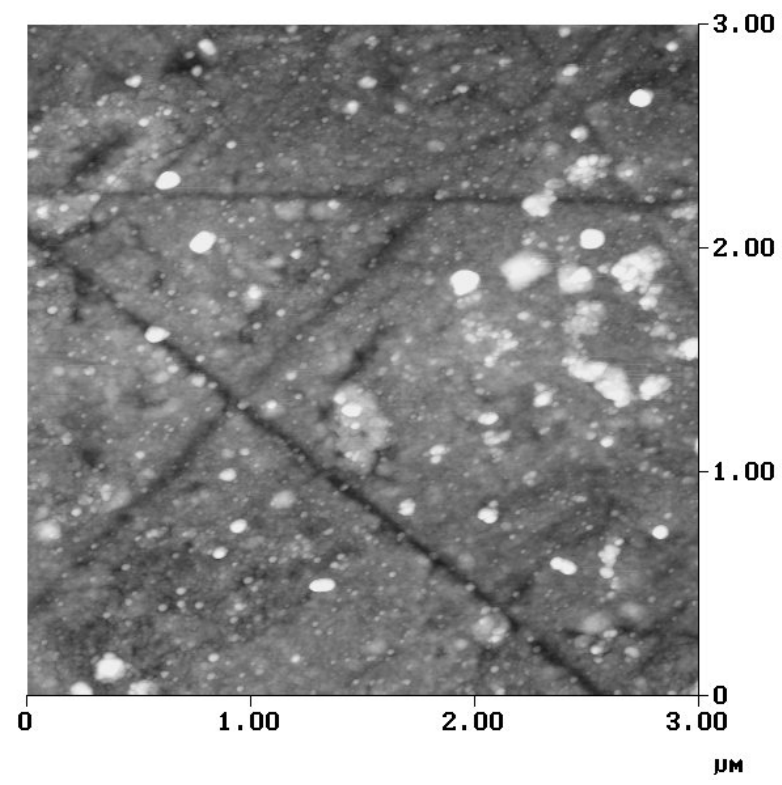

Fig. 15. Atomic force micrograph $(3 \mu \mathrm{m} \times 3 \mu \mathrm{m} \times 50 \mathrm{~nm})$ of a PEA film deposited on $\mathrm{Ni}$ at the potential of peak I and annealed at $400^{\circ} \mathrm{C}$; $[\mathrm{EA}]=0.5 \mathrm{M}$
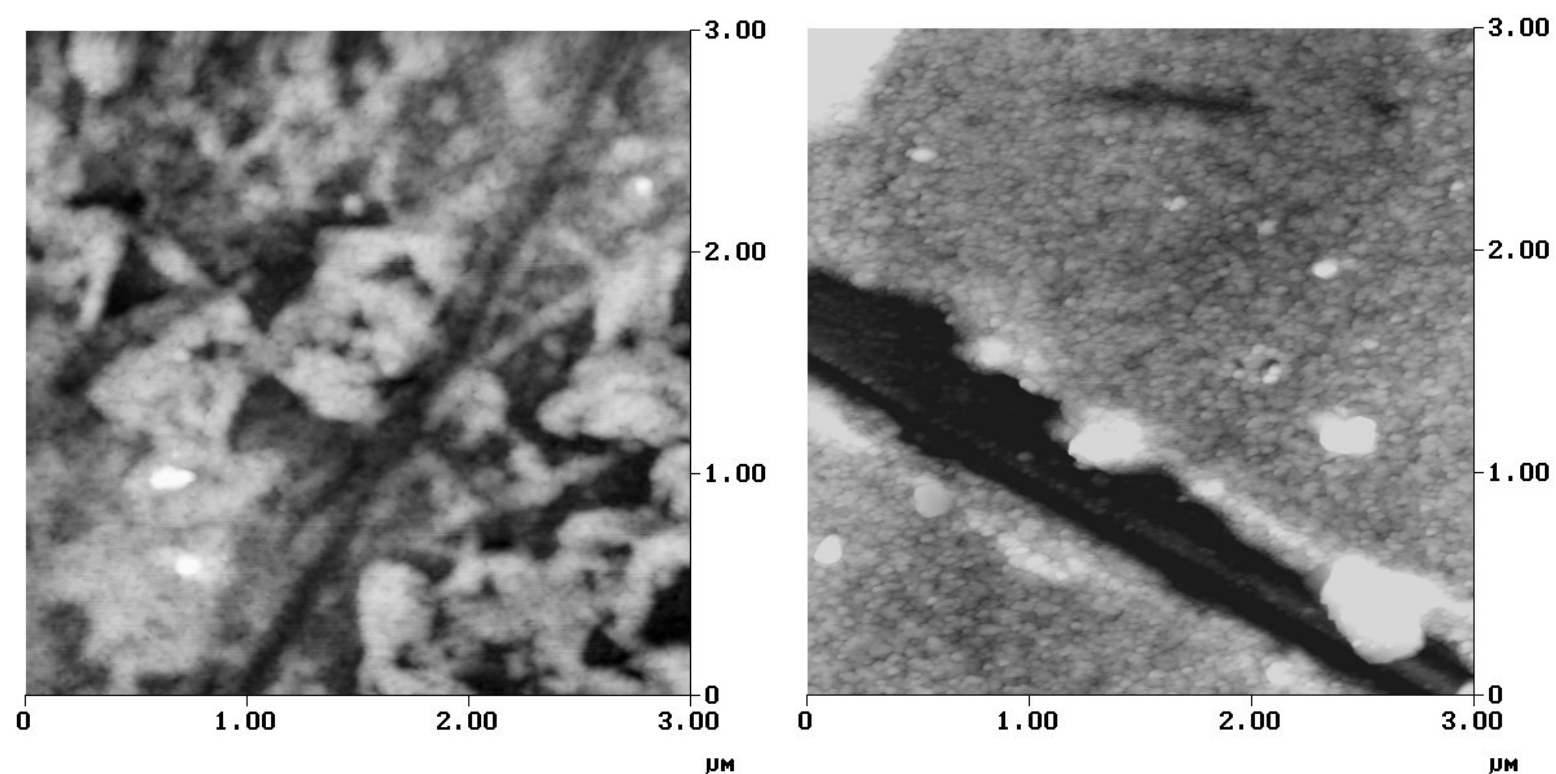

Fig. 16. Atomic force micrographs $(3 \mu \mathrm{m} \times 3 \mu \mathrm{m} \times 50 \mathrm{~nm})$ of films deposited on $\mathrm{Ni}$ at the potential of peak I and annealed at $400^{\circ} \mathrm{C}$; A) left: PAN film, $[A N]=0.5 \mathrm{M}$; B) right: mixed PEA/PAN film, $[A N]=[E A]=0.5 \mathrm{M}$

It is remarkable that the morphology of the annealed mixed PEA/PAN coating (20 wt.-\% of PAN, Tab. 3) is completely different from the morphology of the constitutive polymers under the same conditions (Fig. 16B). The surface remains indeed granular and the grains (that basically retain their average size) become better defined, which increases the surface roughness. The PEA chains are, therefore, thought to be intimately mixed with the PAN within the grains, preventing them from fusing into larger aggregates and restricting the film shrinkage. Cracks observed on the surface of this film before annealing (Fig. 13B) have grown in width and in depth to the point where the metal is now visible, making an AFM estimate of the film thickness possible, c. $30 \mathrm{~nm}$. This small thickness compared to data for untreated PEA and 
PAN films (Tab. 1) is consistent with the loss of matter, which does not create local heterogeneities, except for the growth of the original cracks. This general behaviour is in favour of the homogeneity of the film composition.

\section{Concluding remarks}

This paper has compared the main characteristics of electrografted PAN and PEA films. Ellipsometry has shown that PEA films are thicker than PAN films prepared under similar conditions. Observed by AFM, the morphology of PAN films is typically granular likely as a result of the chain collapse onto the metal surface before ex situ analysis and because of the high $T_{\mathrm{g}}$ of this polymer. In contrast, PEA films are featureless because of their rubbery character; the mobile chains can spread over the nickel surface, as a wetting liquid would do.

The possibility to prepare mixed PEA/PAN coatings by sequential electropolymerization of each monomer on the same cathode has been investigated. Although voltammetric curves show that the second monomer can be electrografted on a cathode previously passivated by the first one, the success of the technique strongly depends on the polymerization sequence of the monomers. When PAN is grafted first, the electropolymerization of EA is conducted at a more cathodic potential than AN, which results in the degrafting of the originally bound PAN chains and final formation of a PEA film. When the polymerization sequence is reversed, the PEA chains are not degrafted at the less cathodic potential required by AN electrografting. A second reason for the successful formation of mixed PEA/PAN films under these conditions can be found in the grafting density of PEA, which is small enough for leaving cathodic sites available to adsorption of AN. The solvation of the grafted PEA chains by the AN/DMF solution also makes diffusion of AN and growing PAN chains easier through the originally grafted PEA layer.

The morphology of the mixed films observed by AFM is surprising since even at low PAN content, the typical granular structure of PAN films is preserved. Therefore, the minor thermoplastic component dictates the morphology to the major rubbery polymer. Even when TOF-SIMS analysis detects the two polymers at the surface of some mixed films, no microphase separation can be observed by AFM on the nanometer scale. Although indirect, the conclusion is that the two polymers are intimately mixed within the film, a conclusion consistent with the effect of the selective thermal degradation of PEA on the film morphology.

In the case of films of PEA (or rich in PEA), the intrinsic mobility of this polymer $\left(T_{\mathrm{g}}=\right.$ $-24^{\circ} \mathrm{C}$ ) allows it to spread over the whole metal surface including defects (grooves, holes, etc.). This is favourable with regard to protection of the metal surface.

\section{Experimental part}

\section{Electrochemistry}

The potentiostat, electrochemical cell, and the general procedure for electrode and solution preparation have been described elsewhere [7]. Potentials were measured against a pseudo-reference Pt electrode. The area of the indicator electrode (Ni) was $2 \mathrm{~cm}^{2}$ in all experiments. The oxide at the surface of the nickel electrode was electrochemically reduced in an acetonitrile/tetraethylammonium perchlorate (ACN/TEAP) solution in the glove box, prior to the use of the electrode in a monomer 
containing solution. All experiments were conducted under dry conditions (10 ppm water) in a glove box under inert atmosphere.

Electrochemical experiments were carried out with acrylonitrile and ethyl acrylate $(0.5$ to $2.5 \mathrm{M})$, dissolved in DMF with TEAP $\left(5 \cdot 10^{-2} \mathrm{M}\right)$ added as a conducting salt.

All samples were prepared by voltammetry $(20 \mathrm{mV} / \mathrm{s})$ in the potential range of peak $\mathrm{I}$. The final potential was taken just beyond the top of that peak. Three kinds of coatings were prepared: PAN, PEA, and mixed PAN/PEA coatings. PAN and PEA coatings were prepared by two successive potential scans carried out in a single cell containing either AN or EA, the electrolysis time at the final potential not exceeding $30 \mathrm{~s}$. The same general procedure was used for the preparation of mixed PAN/PEA coatings, except that the first scan was carried out in a cell containing one monomer and the second scan in a separate cell containing the second monomer. In this case, the cathode was rinsed with DMF before the second scan was conducted, in order to avoid contamination of the second monomer by the first one.

All polymer coatings were carefully washed with DMF, a good solvent for PAN and PEA, then with acetonitrile and finally dried for $12 \mathrm{~h}$, at $40^{\circ} \mathrm{C}$, in a vacuum oven. They were stored under nitrogen before characterization.

\section{Characterization}

Polymer films were characterized by IR reflection-absorption spectroscopy (IRRAS) at a grazing angle of $7^{\circ}$, using a Bruker (Equinox IFS 66) spectrometer equipped with a polarizer (Specac KRS-5). Spectra were recorded in the 500 to $4000 \mathrm{~cm}^{-1}$ frequency range (resolution of $2 \mathrm{~cm}^{-1}$ ). The composition of the mixed PEA/PAN coatings was calculated by using a calibration curve, as detailed elsewhere [26].

Polymer films were also analyzed by TOF-SIMS. The experimental system (spectrometer from Charles Evans \& Associates [34,35]) has been detailed elsewhere [36]. The sample was bombarded by pulsed ${ }^{69} \mathrm{Ga}^{+}$ions $(15 \mathrm{keV})$ and the secondary ions were accelerated up to $\pm 3 \mathrm{keV}$ by applying a bias on the sample. The spread in initial energies of the secondary ions was compensated by deflection in three electrostatic analyzers. A surface area of $85 \mu \mathrm{m} \times 85 \mu \mathrm{m}$ was analyzed for the samples. The data acquisition time was $5 \mathrm{~min}$ and the total ion dose per spectrum was $c .10^{12} \mathrm{ions} / \mathrm{cm}^{2}$, which is lower than the usually accepted dose for static conditions [37]. No charge effect was detected for the investigated samples. The software developed by Charles Evans \& Associates [34] was used for data acquisition and treatment. The best mass resolution was $M / \delta M \approx 11000$ at $\mathrm{m} / \mathrm{z}=28$ on a Si wafer. Under the conditions of this study, the mass resolution was about 5000 at $\mathrm{m} / \mathrm{z}=29$, which allows to separate the different contributions appearing in the peak at a given nominal mass (molecular or atomic ions with different chemical compositions, e.g., hydrocarbons, oxygen or nitrogen containing fragments, and having a mass difference of only a few $10^{-2} \mathrm{Da}$ ).

AFM measurements were performed using a NanoScope III apparatus (Digital Instruments), in contact or tapping mode, with commercially available cantilevers. All measurements were carried out in air at ambient temperature. Several locations on the surface of each sample were imaged, in order to ensure the reproducibility of the observations.

Ellipsometry was carried out with a commercially available Ellisel ellipsometer (type: fixed polariser / rotating compensator / fixed analyzer) from Jobin-Yvon/Sofie instrument, operating at a wavelength of $632.8 \mathrm{~nm}$ (helium-neon laser). The ellipsometric 
azimuth $(\psi)$ and phase $(\Delta)$ angles were measured with the analyzer at $+45^{\circ}$ and $-45^{\circ}$ with respect to the plane of incidence, in order to compensate for systematic errors (imperfections and residual misalignment of the optical components) [38]. Film thickness was measured at $70.3^{\circ}$ (incidence angle with respect to the normal of the substrate), and confirmed at $55.5^{\circ}$. A model consisting of a homogeneous layer on a flat substrate was used to fit the experimental data [17]. The complex refractive index of nickel was fixed at $2.11+\mathrm{i} 3.94$ [17]. The refractive index for PAN [17] and PEA was 1.91 and 1.47 , respectively [22].

\section{Thermal treatment}

The samples were heated in an oven at a rate of $5^{\circ} \mathrm{C} / \mathrm{min}$, up to $400^{\circ} \mathrm{C}$ for $1 \mathrm{~h}$ under flowing nitrogen.

Acknowledgement: This work was supported in Liège and Mons by the 'Services Fédéraux des Affaires Scientifiques, Techniques et Culturelles' (SSTC) in the frame of 'Pôles d'Attraction Interuniversitaires' (Chimie Supramoléculaire et Catalyse Supramoléculaire-PAI4/11). CJ is Research Associate of the FNRS. JLB and coll. are indebted to FNRS-FRFC. XA thanks the 'Direction Générale de la Recherche Scientifique de la Communauté Française de Belgique' (convention 94/99-173) for financial support. The 'Fonds National de la Recherche Scientifique' FNRS and the 'Région Wallonne' (Belgium) are also gratefully acknowledged for the purchase of the TOF-SIMS spectrometer and the ellipsometer by the research laboratories in Louvain. NB is indebted to Dr. L. Martinot and Prof. P. Teyssié for fruitful discussions, and to D. Labaye for his collaboration.

[1] Schmidt, R. G.; Bell, J. P.; Adv. Polym. Sci. 1986, 75, 33.

[2] Benoist, P.; Legeay, G.; Morello, R.; Poncin-Epaillard, F.; Eur. Polym. J. 1992, 28, 1383.

[3] Doblhofer, K.; Bull. Electrochem. 1992, 8, 73.

[4] Saraç, A.; Ozkara, S.; Ustamehmetaghu, B.; Ozgur, G.; J. Polym. Sci., Part A: Polym. Chem. 1999, 37, 2319.

[5] Lécayon, G.; Le Gressus, C.; Le Moel, A.; Eur. Patent no. 0038244, 1981.

[6] Lécayon, G.; Bouizem, Y.; Le Gressus, C.; Reynaud, C.; Boiziau, C.; Juret, C.; Chem. Phys. Lett. 1982, 91, 506.

[7] Mertens, M.; Calberg, C.; Martinot, L.; Jérôme, R.; Macromolecules 1996, 29, 4910.

[8] Mertens, M.; Calberg, C.; Baute, N.; Jérôme, R.; Martinot, L; J. Electroanal. Chem. 1998, 441, 237.

[9] Baute, N.; Martinot, L.; Jérôme, R.; J. Electroanal. Chem. 1999, 472, 83.

[10] Martinot, L.; Mertens, M.; Lopes, L.; Faack, P.; Krausch, M.; Guillaume, J.; Ghitti, G.; Marien, J.; Riga, J.; Jérôme, R.; Schrijnemackers, J.; Radiochimica Acta 1996, 75, 111.

[11] Houzé, F.; Boyer, L.; Noël, S.; Viel, P.; Lécayon, G.; Bourin, J.-M.; Synth. Met. 1994, 62, 207. 
[12] Tanguy, J.; Deniau, G.; Augé, C.; Zalczer, G.; Lécayon, G.; J. Electroanal. Chem. 1994, 377, 115.

[13] Baute, N.; Teyssié, P.; Martinot, L.; Mertens, M.; Dubois, P.; Jérôme, R.; Eur. J. Inorg. Chem. 1998, 1711.

[14] Crispin, X.; Lazzaroni, R.; Geskin, V.; Baute, N.; Dubois, P.; Jérôme, R.; Brédas, J. L.; J. Am. Chem. Soc. 1999, 121, 176.

[15] Poleunis, C.; Bertrand, P.; Calberg, C.; Mertens, M.; Jérôme, R.; Proceedings of the Second International Conference on Polymer-Solid Interfaces: From model to real systems, Namur, Belgium 1996, p. 383.

[16] Viel, P.; de Cayeux, S.; Lécayon, G.; Surf. Interface Anal. 1993, 20, 468.

[17] Calberg, C.; Mertens, M.; Jérôme, R.; Arys, X.; Jonas, A.; Legras, R.; Thin Solid Films 1997, 310, 148.

[18] Newton, P.; Houzé, F.; Guessab, S.; Noël, S.; Boyer, L.; Lécayon, G.; Viel, P.; Thin Solid Films 1997, 200.

[19] Calberg, C.; Mertens, M.; Baute, N.; Jérôme, R.; Carlier, V.; Sclavons, M.; Legras, R.; J. Polym. Sci., Part B: Polym. Phys. 1998, 36, 543.

[20] Kubasova, N. A.; Suan Din, D.; Heiderich, M. H.; Schishkina, M. V.; Polym. Sci. USSR 1971, 13, 184.

[21] Charlier, J.; Bureau, C.; Lecayon, G.; J. Electroanal. Chem. 1999, 465, 200.

[22] Baute, N.; Jérôme, C.; Martinot, L.; Mertens, M.; Geskin, V. M.; Lazzaroni, R.; Brédas, J. L.; Jérôme, R.; Eur. J. Inorg. Chem. 2001, 1097.

[23] Bandrup, J.; Immergut, E. H.; Polymer Handbook, $3^{\text {rd }}$ edition, John Wiley \& Sons, New-York 1989.

[24] Yamazaki, N.; Adv. Polym. Sci. 1969, 6, 377.

[25] Grassie, N.; Speakman, J. G.; Davis, T. I.; J. Polym. Sci., Part A1 1971, 9, 931.

[26] Geskin, V.; Lazzaroni, R.; Baute, N.; Jérôme, R.; Brédas, J. L, "Forum des Microscopies a Sonde Locale", Lilles, France 1998.

[27] Aspnes, D. E.; Theeten, J. B.; Hottier, F.; Phys Rev B 1979, 20, 3292.

[28] Granqvist, G.; Hunderi, O.; Phys Rev B 1977, 16, 3513.

[29] Vickerman, J. C.; Briggs, D.; Henderson, A.; in "The Wiley Static SIMS Library", vol. 2, Wiley, Chichester 1996.

[30] Leclère, Ph.; Lazzaroni, R.; Brédas, J. L.; Yu, J. M.; Dubois, Ph.; Jérôme, R.; Langmuir 1996, 12, 4317.

[31] Fitzer, E.; Carbon 1989, 27, 621.

[32] Alexander, M. R.; Jones, F. R.; Surf. Interface Anal. 1994, 22, 230.

[33] Krigbaum, W. R.; Tokita, N.; J. Polym. Sci. 1960, 43, 467.

[34] Schueler, B.; Sander, P.; Reed, D. A.; Vacuum 1990, 41, 1661.

[35] Schueler, B.; Microsc. Microanal. Microstruct. 1992, 3, 1.

[36] Bertrand, P.; Weng, L.T.; Mikrochim. Acta 1996, 13, 167.

[37] Briggs, D.; Hearn, M. J.; Vacuum 1986, 36, 1005.

[38] Kleim, R.; Kuntzler, L.; El Ghemmaz, A.; J. Opt. Soc. Am. A 1994, 11, 2550. 